\title{
Use of Shear Wave Elastography to Diagnose Acute Pancreatitis: A Cross-sectional Study
}

\section{ABSTRACT}

Introduction: Acute inflammation process of the pancreas with or without involvement of surrounding tissues and remote organ systems is termed as Acute Pancreatitis (AP). Contrast Enhanced Computed Tomography (CECT) if performed immediately may underestimate the severity. Therefore, ultrasound examination remains the first imaging diagnostic method in suspected cases of AP. The sensitivity of B-mode sonography for the early diagnosis of AP can be increased by the detection of an increase in pancreatic tissue stiffness with Shear Wave Elastography (SWE).

Aim: To evaluate the efficacy of SWE in the analysis of AP.

Materials and Methods: A cross-sectional study was conducted in Tertiary Care Hospital attached to Mysore Medical College and Research Institute, Mysuru, Karnataka, India, from August 2019 to September 2019. The pancreatic parenchyma of 30 patients with symptoms of AP that included acute onset of severe central epigastric pain, poorly localised tenderness and pain increased by supine positioning radiating to the back. The study also included 40 healthy, asymptomatic volunteer who were examined using B-mode sonography and SWE. Computed Tomography (CT) was performed in all patients with AP with a
SEIMENS SOMATOM DEFINITION EDGE 128 slice CT scanner. Elastographic measurements were performed and quantitative SWE values represented in kilopascal $(\mathrm{kPa})$ of the patients and asymptomatic volunteers group were compared. Patients' amylase and lipase levels were done by biochemical tests. Descriptive and Inferential statistical analysis was carried out in the present study. Student's t-test (two tailed, independent), Leven's test for homogeneity of variance and Chi-square test was used to find the significance of study parameters.

Results: The mean SWE values for the asymptomatic volunteers with normal pancreatic parenchyma were $9.53 \pm 2.62 \mathrm{kPa}$. The mean SWE values for the pancreatic parenchyma of the patients with AP were $17.23 \pm 6.24 \mathrm{kPa}$. The mean SWE value for the patients with AP was significantly higher than the value for the control group $(p<0.001)$. A SWE cut-off value of $13.5 \mathrm{kPa}$ was associated with $70 \%$ sensitivity and $92.5 \%$ specificity for diagnosis of AP.

Conclusion: For the diagnosis of AP at initial hospital admission, SWE can be used as it is a rapid, radiation-free, and noninvasive tool. It is a useful imaging method with high sensitivity and specificity for the diagnosis of AP.

Keywords: Computed tomography, Pancreas, Sonography

\section{INTRODUCTION}

AP can be defined as acute inflammation process of the pancreas with or without involvement of surrounding tissues and remote organ systems. It is associated with elevated pancreatic enzyme levels in blood and/or urine [1]. It is most frequently caused by gallstone disease or excess alcohol ingestion. Patients present with characteristic symptoms which are usually diagnostic, often with elevated serum pancreatic enzymes. Imaging may be necessary to rule out other causes of abdominal pain, confirm the diagnosis of pancreatitis, identify the cause of pancreatitis, or to evaluate for complications such as necrosis or pseudocysts [2].

A combination of clinical, laboratory and radiological findings is required for the diagnosis of AP. Two of the following three features are suggested by a number of International guidelines for the diagnosis:

- Abdominal pain (persistent severe epigastric pain with acute onset often radiating to the back).

- $\quad$ Serum lipase activity (or amylase activity) at least three times higher than the normal upper limit.

- $\quad$ Characteristic imaging findings on abdominal USG (a CT scan or MRI are taken if the diagnosis is uncertain) $[3,4]$.

If serum amylase and/or lipase activity is normal that is less than three times the upper limit but abdominal pain is strongly suggestive of $\mathrm{AP}$, characteristic imaging findings on a CECT or MRI are required for the diagnosis [5].
AP can be reliably diagnosed on CECT which also shows the extent of disease severity. The best time for CECT examination in AP is not well known $[6,7]$. If done immediately after symptom onset, pancreatic damage and its severity may be underestimated, but if done five days later and CECT reveals a normal pancreas or only mild inflammation (fat stranding) surrounding the pancreas a severe form of acute pancreatitis can be ruled out [8].

Ultrasonography examinations represent the first imaging diagnostic method in patients with suspicion of AP even though CT and Magnetic Resonance Imaging (MRI) scans represent the efficient methods in evaluating patients with AP [9-11].

Reliable radiologic techniques are required for the diagnosis of $\mathrm{AP}$ on admission because early diagnosis and treatment are important in improving patient outcomes. SWE is a new imaging method that is non-invasive, real-time and reproducible. Based on tissue stiffness, it offers quantitative assessment and provides information correlating to histological changes in tissues [12,13]. Reference area is not needed with SWE for evaluation of the stiffness; therefore, it is suitable for the diagnosis of stiffness in a variety of diseases [13]. The sensitivity of B-mode sonography for the early diagnosis of AP can be increased by the detection of an increase in pancreatic tissue stiffness with SWE [1216]. With this background, present study was conducted with an aim to determine the efficacy of SWE in the diagnosis of acute pancreatitis.

\section{MATERIALS AND METHODS}

A cross-sectional study was done after Institutional Ethical Committee (IEC) approval (ECR/134/InstKA/2013/RR-19) was obtained. The main 
sources of data for the study were patients attending Mysore Medical College and Research Institute, Mysuru, Karnataka, India, and referred to the Radiology Department. The study was conducted from August 2019 to September 2019.

\section{Inclusion Criteria}

Accompanying epigastric pain with either one of them

- Serum amylase and lipase levels greater than three times the upper limit of normal or:

- On ultrasound examination, altered echogenicity of the pancreas, and increase in the pancreatic size of the pancreas (both focal and diffuse).

\section{Exclusion Criteria}

- Patients with pregnancy, chronic pancreatitis, a history of pancreatitis, malignancy, chronic liver disease, a mass involving pancreas mass, or obesity $\left(\mathrm{BMl}>30 \mathrm{~kg} / \mathrm{m}^{2}\right)$

\section{- Poor visualisation of the pancreas on B-mode sonography}

After taking informed consent, laboratory tests were performed in 30 symptomatic patients with AP. The pancreas of all patients and asymptomatic volunteers were assessed with B-mode ultrasonography and SWE imaging. B-mode ultrasonography examination was performed using 1-5.0 MHZ high frequency curvilinear transducer (C5-I) in PHILIPS Affiniti 70 ultrasound machine. B-mode ultrasonography examination of the pancreas was performed in transverse, longitudinal, and angled oblique scanning in the supine position. Patients were screened using the spleen as an acoustic window in the left lateral plane, when the epigastric area of the pancreatic tail could not be adequately visualised on transverse plane ultrasound. Pancreatic echoes, parenchymal thickness, the pancreatic duct and peripancreatic areas were evaluated. Presence of gallbladder and common bile duct stones was also assessed using B-mode ultrasonography.

In the AP group, decreased echogenicity of the pancreatic parenchyma, increased pancreatic volume, focal intrapancreatic echo changes, heterogeneous parenchyma, peripancreatic fluid, and peripancreatic fat stranding (i.e., inflammatory changes in peripancreatic soft tissues) were investigated. Normal and abnormal ultrasonography findings of the pancreas in asymptomatic volunteers and AP patients were established based on the studies conducted by Sirli R and Sporea I, and Finstad TA et al., $[17,18]$.

SWE was performed after the B-mode sonography. Ultrasound elastography was performed to all the patients using SWE (Elast PQR technique) in Philips Affiniti 70 machine (PHILIPS medical systems, bothell, WA) using 1-5.0 MHZ high frequency curvilinear transducer (C5-I).

SWE was done in all patients based on a standard procedure. It was done from the epigastric fossa in a supine or semi-sitting position. The Region Of Interest (ROI) was kept at the head or body of the pancreatic parenchyma and as shear waves are easily refracted and reflected, it was chosen at the most clearly visualised region of the pancreas on grey scale imaging that was not near gaseous or liquid component, such as a blood vessel or the stomach [Table/Fig-1]. If the SWE value was $0.00 \mathrm{kPa}$, it was deemed invalid. Rest values were deemed as valid, and measurements were repeated until a
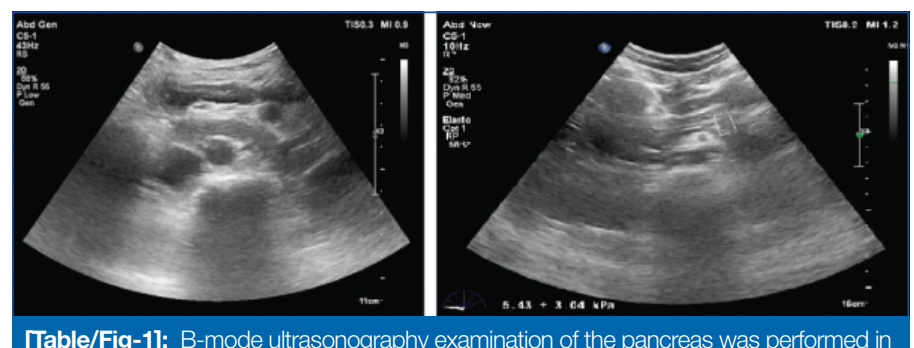

[Table/Fig-1]: B-mode ultrasonography examination of the pancreas was performed in the supine position. Shear Wave Elastography (SWE) was performed after the B-mode sonography. valid value was got at least five times in each case. The median value of the five measurements was taken as the Pancreatic Elastic Modulus (PEM), and the results are presented in $\mathrm{kPa}$ [19].

After ultrasonography examination, CECT was performed with a SEIMENS SOMATOM DEFINITION EDGE 128 slice CT scanner in AP group, within the first 72 hours of admission. All patients received intravenous non-ionic contrast medium. Images reconstructed with 1-mm slice thickness. The CT criteria for AP were as follows:

- An increase in the size of the pancreas, irregular and shaggy pancreatic contours,

- Peripancreatic oedema and fluid,

- Hypo-enhancing heterogeneous parenchyma, and/or pancreatic necrosis.

\section{STATISTICAL ANALYSIS}

The statistical software namely Statistical Package for the Social Sciences (SPSS) 22.0, and R environment ver. 3.2.2 were used for the analysis of the data and Microsoft word and Excel have been used to generate graphs, tables etc., [20-23]. Descriptive and inferential statistical analysis has been carried out in the present study. Significance was assessed at $5 \%$ level of significance.

Student's t-test (two tailed, independent), Chi-square have been used to find the significance of study parameters. Non-parametric setting for qualitative data analysis has been used; Leven's test for homogeneity of variance has been performed to assess the homogeneity of variance.

\section{RESULTS}

The patient group included 7 (23.3\%) male and 23 (76.7\%) female patients (mean age, $36.2 \pm 8.0$ years), and the control group was composed of 28 (70\%) female and 12 (30\%) male participants (36.5 \pm 10.0 years) [Table/Fig-2].

\begin{tabular}{|c|c|c|c|c|c|}
\hline \multicolumn{2}{|c|}{$\begin{array}{l}\text { Demographic } \\
\text { variable }\end{array}$} & $\begin{array}{l}\text { Cases } \\
(n=30)\end{array}$ & $\begin{array}{l}\text { Controls } \\
(n=40)\end{array}$ & Total $(n=70)$ & $\begin{array}{l}\text { Test for } \\
\text { matching }\end{array}$ \\
\hline \multirow{7}{*}{$\begin{array}{l}\text { Age (in } \\
\text { years) }\end{array}$} & $\leq 20$ & 0 & 1 (2.5\%) & $1(1.4 \%)$ & \multirow{6}{*}{$\begin{array}{c}\chi^{2} \text { value: } 3.254 \\
\text { df: } 4 \\
\text { p-value: } 0.516\end{array}$} \\
\hline & $21-30$ & 8 (26.7\%) & 11 (27.5\%) & $19(27.1 \%)$ & \\
\hline & $31-40$ & 15 (50.0\%) & $13(32.5 \%)$ & $28(40.0 \%)$ & \\
\hline & $41-50$ & 6 (20.0\%) & $12(30.0 \%)$ & 18 (25.8\%) & \\
\hline & $\geq 51$ & $1(3.3 \%)$ & $3(7.5 \%)$ & $4(5.7 \%)$ & \\
\hline & Total & 30 (100\%) & 40 (100\%) & 70 (100\%) & \\
\hline & Mean $\pm S D$ & $36.2 \pm 8.0$ & $36.5 \pm 10.0$ & $36.3 \pm 9.1$ & p-value: $0.890^{*}$ \\
\hline \multirow{3}{*}{ Sex } & Male & 7 (23.3\%) & 12 (30.0\%) & 19 (27.1\%) & \multirow{3}{*}{$\begin{array}{c}\chi^{2} \text { value: } 0.385 \\
\text { df: } 1 \\
\text { p-value: } 0.535\end{array}$} \\
\hline & Female & $23(76.7 \%)$ & 28 (70.0\%) & 51 (72.9\%) & \\
\hline & Total & 30 (100\%) & 40 (100\%) & 70 (100\%) & \\
\hline
\end{tabular}

[Table/Fig-2]: Distribution of study participants based on demographic features. *Independent samples t-test; Interpretation: Controls were matched to cases with respect to age and sex. This is testified with the $p$-values being $>0.05$ for both the variables

On B-mode ultrasound examination, 26 (86.7\%) patients had bulky pancreas, 21 (70\%) patients had decreased echogenicity and $10(33.3 \%)$ patients had additional gall/biliary stones [Table/Fig-3].

\begin{tabular}{|l|c|c|}
\hline USG findings & No of cases $(\mathrm{n})$ & Percentage (\%) $^{*}$ \\
\hline Bulky pancreas & 26 & 86.7 \\
\hline Decreased echogenicity & 21 & 70.0 \\
\hline Heterogeneous appearance & 16 & 53.3 \\
\hline Peri-pancreatic fluid & 11 & 36.7 \\
\hline Gall/Biliary stones & 10 & 33.3 \\
\hline \\
[Table/Fig-3]: Findings of abdominal ultrasonography of cases (N-30). \\
*Total \% does not add up to 100\% since the findings are not mutually exclusive
\end{tabular}

The SWE measurements for the asymptomatic volunteers with normal pancreas were from 5.2-15.8 $\mathrm{kPa}$ (mean, 9.53 \pm 2.62 ). The SWE measurements for the pancreas in AP group were from 5.3 
to $29.3 \mathrm{kPa}$ (mean, 17.23 \pm 6.24 ). The mean SWE measurements in AP group was significantly greater than that in the control group $(p<0.001)[$ Table/Fig-4]. The cut-off values of SWE for AP, sensitivity and specificity and ROC curve of SWE values of AP are shown in [Table/Fig-5]. A SWE cut-off value of $13.5 \mathrm{kPa}$ was associated with $70 \%$ sensitivity and $92.5 \%$ specificity for diagnosis of AP.

\begin{tabular}{|c|c|c|c|c|}
\hline \multirow{2}{*}{$\begin{array}{l}\text { Speed of } \\
\text { shear wave } \\
\text { (in } \mathrm{kPa} \text { ) }\end{array}$} & $\begin{array}{l}\text { Cases } \\
(\mathrm{n}=30)\end{array}$ & $\begin{array}{c}\text { Controls } \\
(n=40)\end{array}$ & Total & \multirow[b]{2}{*}{$\begin{array}{c}\text { Test of } \\
\text { significance }\end{array}$} \\
\hline & $\begin{array}{l}\text { Frequency } \\
(\%)\end{array}$ & $\begin{array}{c}\text { Frequency } \\
(\%)\end{array}$ & $\begin{array}{c}\text { Frequency } \\
(\%)\end{array}$ & \\
\hline $0-10$ & $5(16.7)$ & $29(72.5)$ & 34 (48.6) & \multirow{4}{*}{$\begin{array}{c}\chi^{2} \text { value: } 26.672 \\
\text { df: } 1 \\
\text { p-value: }<0.001\end{array}$} \\
\hline $10-20$ & $15(50.0)$ & $11(27.5)$ & $26(37.1)$ & \\
\hline 20-30 & $10(33.3)$ & 0 & $10(14.3)$ & \\
\hline \multirow[t]{3}{*}{ Total } & $30(100)$ & $40(100)$ & $70(100)$ & \\
\hline & Mean $\pm S D$ & Mean $\pm S D$ & Mean \pm SD & \multirow{2}{*}{$\begin{array}{c}\text { t statistic: } 7.032^{*} \\
\text { df: } 68 \\
\text { p-value: }<0.001\end{array}$} \\
\hline & $17.23 \pm 6.24$ & $9.53 \pm 2.62$ & $12.82 \pm 5.92$ & \\
\hline
\end{tabular}

[Table/Fig-4]: Distribution of study participants based on findings of Shear Wave Elastography (SWE) $(n=70)$

*Independent samples t-test; $p$-value $<0.05$ is considered as significant

\begin{tabular}{|l|c|c|c|c|c|c|c|}
\hline $\begin{array}{l}\text { a. } \\
\text { SWE } \\
\text { cut- } \\
\text { off } \\
\text { (kPa) }\end{array}$ & $\begin{array}{c}\text { Sensitivity } \\
(\%)\end{array}$ & $\begin{array}{c}\text { Specificity } \\
(\%)\end{array}$ & $\begin{array}{c}\text { Positive } \\
\text { PV (\%) }\end{array}$ & $\begin{array}{c}\text { Negative } \\
\text { PV (\%) }\end{array}$ & $\begin{array}{c}\text { LR+ } \\
(\%)\end{array}$ & LR- (\%) & $\begin{array}{c}\text { Overall } \\
\text { DA (\%) }\end{array}$ \\
\hline 11.00 & 83.3 & 77.5 & 73.5 & 86.1 & 3.70222 & 0.21548 & 80.0 \\
\hline 11.50 & 80.0 & 77.5 & 72.7 & 83.8 & 3.55556 & 0.25806 & 78.6 \\
\hline 12.00 & 73.3 & 77.5 & 71.0 & 79.5 & 3.25778 & 0.34452 & 75.7 \\
\hline 12.50 & 73.3 & 85.0 & 78.6 & 81.0 & 4.88667 & 0.31412 & 80.0 \\
\hline 13.00 & 73.3 & 85.0 & 78.6 & 81.0 & 4.88667 & 0.31412 & 80.0 \\
\hline 13.50 & 70.0 & 92.5 & 87.5 & 80.4 & 9.33333 & 0.32432 & 82.9 \\
\hline
\end{tabular}

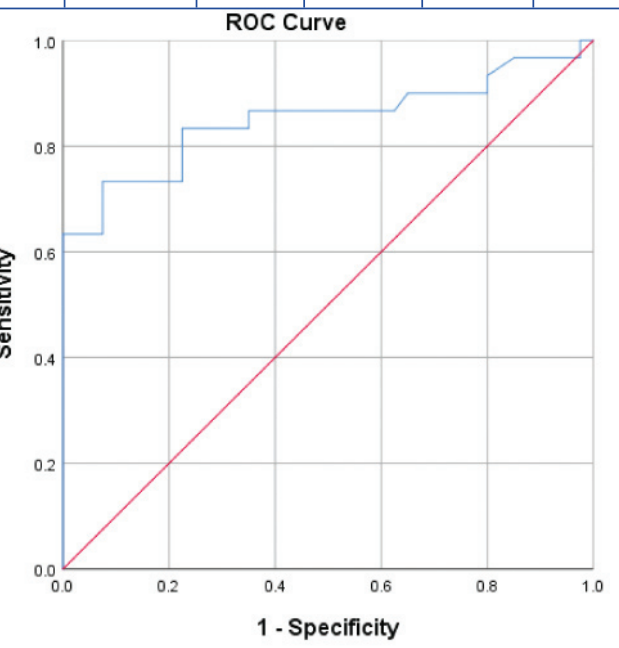

b

Diagonal segments are produced by ties.

[Table/Fig-5]: a) Assessment of effectiveness of SWE for diagnosis of acute pancreatitis. (Gold standard considered: International guidelines for diagnosis) [3,4] b) Reciever Operating Curve (ROC) for assessing diagnostic accuracy of SWE for diagnosis of acute pancreatitis (Gold standard considered: International guidelines for diagnosis).

PV: Predictive value; DA: Diagnostic accuracy; Area under the curve is 0.850 (95\% Confidence interval: 0.747 to 0.954 ; SE: 0.053 ; $p$-value $<0.001$.) Therefore, based on AUC criteria, diagnostic accuracy of SWE is 'very good.' \{i.e., the investigation can be used for diagnosis of Acute Pancreatitis (AP)\}

Serum amylase and lipase of all 30 patients were done. Twenty eight patients had significant elevation, however, two patients showed normal levels [Table/Fig-6].

All 30 patients had some findings on CECT [Table/Fig-7] with most common finding being bulky pancreas in 23 patients, heterogeneous enhancement in 14 patients and peripancreatic fat stranding/fluid in 13 patients, the detailed images of three patients is shown in [Table/Fig-8-10].

\section{DISCUSSION}

Here, all 30 cases (100\%) with AP had a diagnosis by SWE. However, all 30 patients also had features of AP on B-mode ultrasonography

\begin{tabular}{|l|c|c|c|}
\hline & $\begin{array}{c}\text { Significant raise in } \\
\text { lipase and amylase } \\
\text { levels }\end{array}$ & $\begin{array}{c}\text { Significant raise in } \\
\text { lipase with normal } \\
\text { amylase levels }\end{array}$ & $\begin{array}{c}\text { Normal lipase and } \\
\text { amylase levels }\end{array}$ \\
\hline $\begin{array}{l}\text { No. of } \\
\text { patients }\end{array}$ & $23(76.67 \%)$ & $5(16.67 \%)$ & $2(6.67 \%)$ \\
\hline
\end{tabular}

S.Amylase(normal range 23 - $85 \mathrm{U} / \mathrm{L}$ )

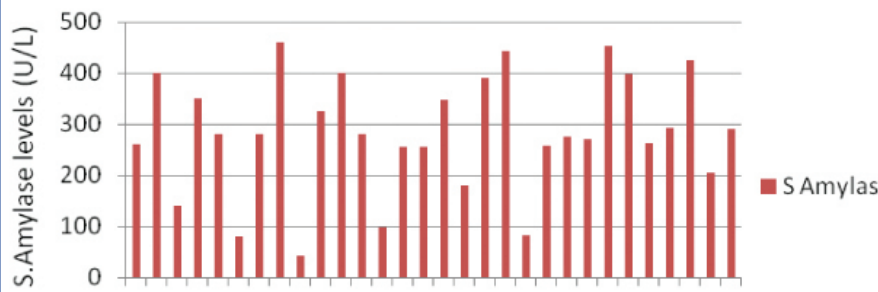

$\begin{array}{lllllllllllllll}1 & 3 & 5 & 7 & 9 & 11 & 13 & 15 & 17 & 19 & 21 & 23 & 25 & 27 & 29\end{array}$

No. of Patients S.Lipase(normal range 13 - $60 \mathrm{U} / \mathrm{L}$ )

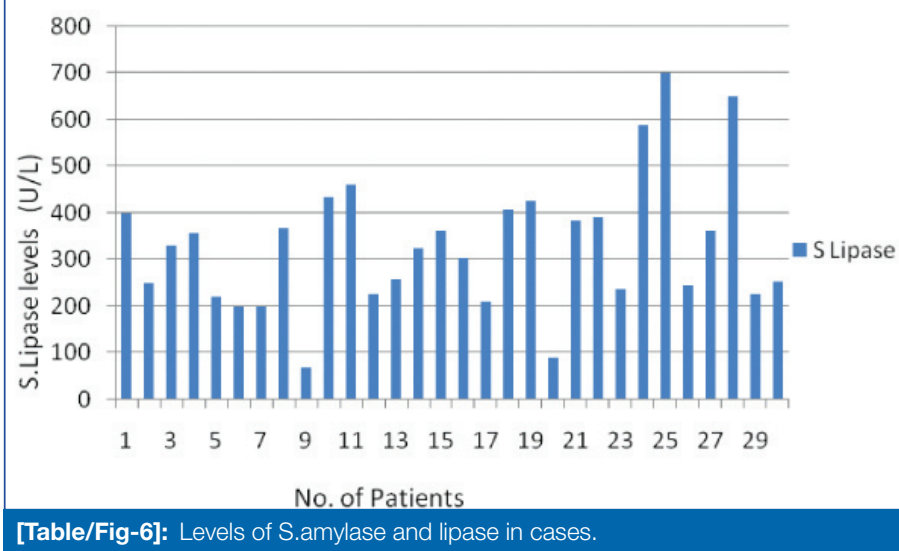

\begin{tabular}{|l|c|c|}
\hline CECT abdomen findings & No of cases (N) & Percentage (\%) \\
\hline Bulky pancreas & 23 & 76.7 \\
\hline Heterogeneous enhancement & 14 & 46.7 \\
\hline Peri-pancreatic fluid & 13 & 43.3 \\
\hline
\end{tabular}
[Table/Fig-7]: Distribution of cases based on findings of CECT abdomen.
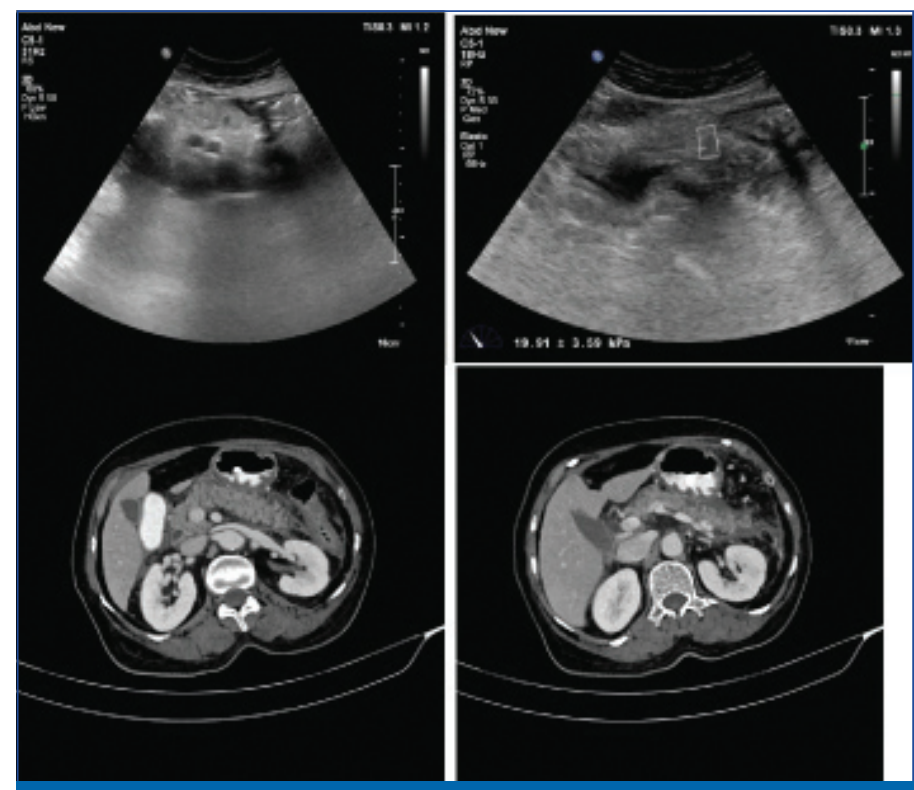

[Table/Fig-8]: A75-year-old female patient with S. Amylase and S. Lipase levels of $349 \mathrm{U} / \mathrm{L}$ and $356 \mathrm{U} / \mathrm{L}$ who presented with epigastric pain and vomiting showed bulky pancreas and peripancreatic fluid collection on B-mode sonography and SWE value of $19.9 \mathrm{kPa}$. On CECT bulky heterogeneous pancreas was found with peripancreatic fluid collection and splenic vein thrombus as well.

and CT examination as well. Only 2 patients out of the 30 patients who had imaging features of AP on B-mode sonography showed normal serum amylase and lipase levels. 

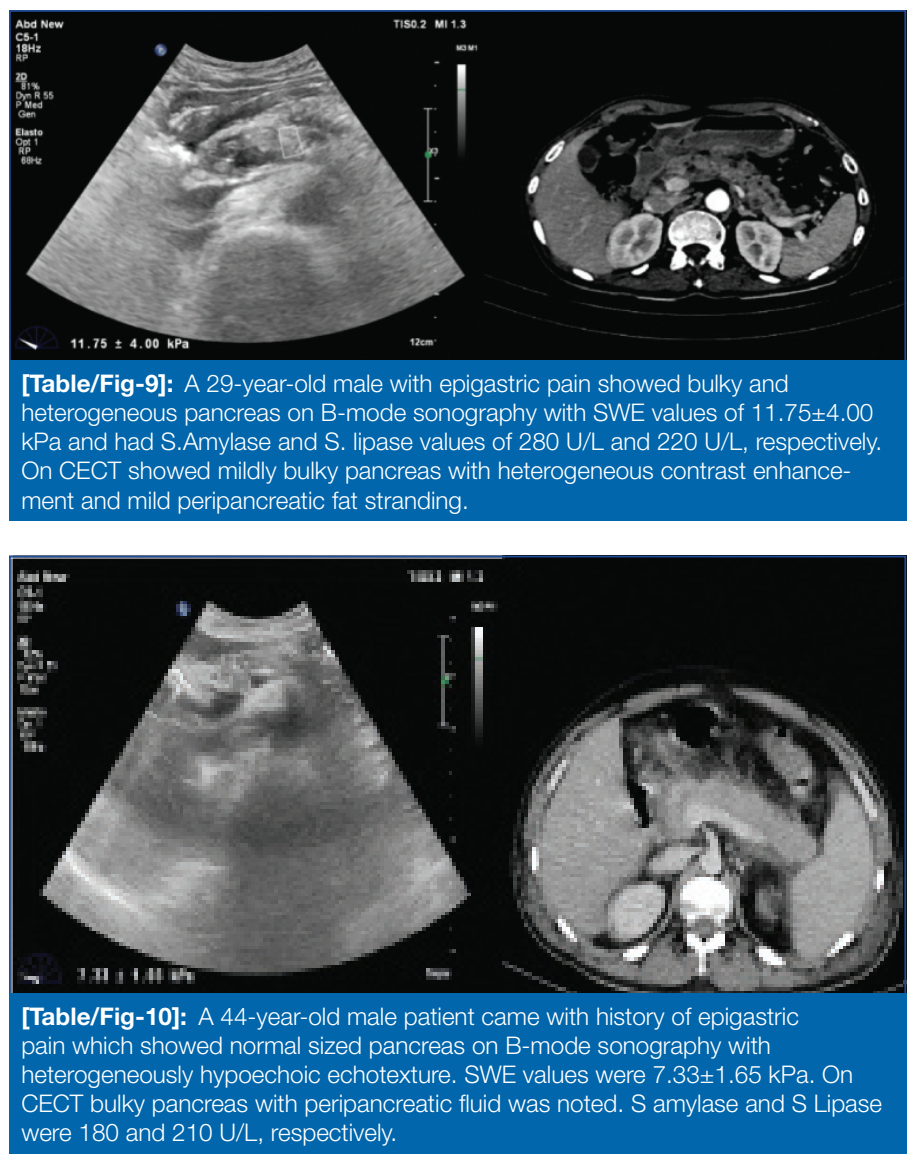

According to a review article by Balthazar EJ ,diagnostic rates for acute pancreatitis on sonography is from $33 \%$ to $90 \%$. It can also be used to identify other causes of pain abdomen. But, diagnosis of acute pancreatitis based on sonography can be difficult in obese patients and patients with flatulence. Computed tomography is used as the primary imaging tool for diagnosis of AP and determination of its severity [10]. The ability to image retroperitoneal organs, abdominal ligaments, the mesentery, the omentum and the pancreas are the advantages of CT. The diagnostic sensitivity of CT for AP ranges from $77 \%$ to $92 \%$ [24-26]. However, in a study conducted by De Sanctis JT et al., they concluded that for initial triage CT was not feasible and that APACHE II score is the most useful and cost effective means with respect to intensity of care indicated. CT then may be performed selectively in patients who fail to defervesce as expected or who have clinical findings suggesting the need for emergent surgical or radiological intervention [24]. Therefore, CT is not recommended in the early course of the disease. In present study, out of 30 patients, seven patients had normal size pancreas with other features of AP and 23 patients had bulky pancreas on CECT.

On SWE, authors found mean SWE values for the asymptomatic volunteers with normal pancreatic parenchyma to be $9.53+2.62 \mathrm{kPa}$. The mean SWE measurements for the pancreas of the AP cases was $17.23+6.24 \mathrm{kPa}$. The mean SWE measurement for the AP cases was significantly higher than the value for the control group.

Durmaz $\mathrm{M}$ et al., conducted a study where, they concluded that AP can be diagnosed with a sensitivity and specificity of $98.0 \%$ when $29.45 \mathrm{kPa}$ was designated as cut-off value and that SWE is superior to B-mode US and CECT in the diagnosis of AP on admission [27].

Göya $\mathrm{C}$ et al., conducted a study on 88 patients with symptoms of AP and 50 healthy control participants. The sensitivity and specificity of SWE were $100 \%$ and $98 \%$, respectively, when a cut-off value of $1.63 \mathrm{~m} / \mathrm{s}$ was used. They concluded that acoustic radiation force impulse elastography could be a helpful instrument for analysis of $\mathrm{AP}$ at initial hospital admission, with a superior success rate than the grayscale sonography and CT [28].

In present study, when compared to S. amylase and lipase levels SWE had a higher ability to diagnose AP. However, because all
30 patients had features on B-mode ultrasound and CT scan, the superiority of SWE over them in diagnosing AP could not be evaluated. But the mean SWE values for AP group were significantly elevated as compared to control group, thus pointing towards its efficacy in diagnosing AP.

\section{Limitation(s)}

First, the quality of the images obtained with SWE depends on the abilities of the operator. Optimal images and quantitative data cannot be obtained from patients with tachycardia, tachypnea or obesity. Since SWE evaluation of the pancreas starts after B-mode sonography authors excluded all cases with poor visualisation of the pancreas. Furthermore for SWE, authors only examined the pancreatic head and body because of the difficulty in visualising the pancreatic tail in the absence of transducer compression. Additionally, the relationship between SWE results and the severity of pancreatitis was not evaluated in terms of morbidity and mortality. Small sample size was another limitation.

\section{CONCLUSION(S)}

SWE is a non-invasive, rapid, radiation-free and reproducible imaging method that can efficiently diagnose AP at hospital admission. Furthermore, it could yield positive diagnosis in patients where normal laboratory values are found.

\section{REFERENCES}

[1] Thoeni R. The revised Atlanta Classification of acute pancreatitis: Its importance for the radiologist and its effect on treatment. Radiology. 2012;262(3):751-64.

[2] Munsell M, Buscaglia J. Acute pancreatitis. Journal of Hospital Medicine. 2010;5(4):241-50.

[3] Banks PA, Bollen TL, Dervenis C, Gooszen HG, Johnson CD, Sarr MG, et al. Acute Pancreatitis Classification Working Group. Classification of acute pancreatitis-2012: Revision of the Atlanta classification and definitions by international consensus. Gut. 2013;62:102-11.

[4] Tenner S, Baillie J, DeWitt J, Vege SS, American College of Gastroenterology. American College of Gastroenterology guideline: Management of acute pancreatitis. Am J Gastroenterol. 2013;108:1400-15.

[5] Bollen TL. Imaging of acute pancreatitis: Update of the revised Atlanta classification. Radiol Clin North Am. 2012;50:429-45.

[6] Banks PA, Freeman ML. Practice guidelines in acute pancreatitis. Am J Gastroenterol. 2006;101:2379-2400.

[7] Morgan DE. Imaging of acute pancreatitis and its complications. Clin Gastroentero Hepatol. 2008;6:1077-85.

[8] Moulton JS. The radiologic assessment ofacute pancreatitis and its complications Pancreas. 1991;6 Suppl 1:S13-22.

[9] Somogyi L, Martin SP, Venkatesan T, Ulrich CD. Recurrent acute pancreatitis: An algorithmic approach to identification and elimination of inciting factors. Gastroenterology. 2001;120:708-17

[10] Balthazar EJ. Acute pancreatitis: Assessment of severity with clinical and CT evaluation. Radiology. 2002;223(3):603-13

[11] Lecesne R, Taourel P, Bret PM, Atri M, Reinhold C. Acute pancreatitis: Interobserver agreement and correlation of CT and MR cholangiopancreatography with outcome. Radiology. 1999;211:727-35.

[12] Hanquinet S, Rougemont AL, Courvoisier D, Rubbia-Brandt L, McLin V, Tempia $M$, et al. Acoustic radiation force impulse (ARFl) elastography for the noninvasive diagnosis of liver fibrosis in children. Pediatr Radiol. 2013;43:545-51.

[13] Rafaelsen SR, Vagn-Hansen C, Sørensen T, Lindebjerg J, Pløen J, Jakobsen A. Ultrasound elastography in patients with rectal cancer treated with chemoradiation. Eur J Radiol. 2013;82:913-17.

[14] Cosgrove DO, Berg WA, Doré CJ, Skyba DM, Henry JP, Gay J, et al. BE1 Study Group. Shear wave elastography for breast masses is highly reproducible. Eur Radiol. 2012;22:1023-32.

[15] Sigrist RMS, Liau J, Kaffas AE, Chammas MC, Willmann JK. Ultrasound elastography: Review of techniques and clinical applications. Theranostics. 2017;7:1303-29.

[16] Hamidi C, Göya C, Hattapoğlu S, Uslukaya O, Teke M, Durmaz MS, et al. Acoustic radiation force impulse (ARFI) imaging for the distinction between benign and malignant thyroid nodules. Radiol Med. 2015;120:579-83.

[17] Sirli R, Sporea I. Ultrasound examination of the normal pancreas. Med Ultrason. 2010;12:62-65

[18] Finstad TA, Tchelepi H, Ralls PW. Sonography of acute pancreatitis: Prevalence of findings and pictorial essay. Ultrasound Q. 2005;21:95-104.

[19] Kuwahara T, Hirooka Y, Kawashima H, Ohno E, Sugimoto H, Hayashi D, et al. Quantitative evaluation of pancreatic tumor fibrosis using shear wave elastography. Pancreatology. 2016;16(6):1063-68.

[20] Bernard Rosner (2000), Fundamentals of Biostatistics. $5^{\text {th }}$ Edition. Duxbury; 80-240.

[21] Robert H Riffenburg (2005), Statistics in Medicine. second edition. Academic press. 85-125. 
[22] Sunder Rao PSS, Richard J. An Introduction to Biostatistics, A manual for students in health sciences. $4^{\text {th }}$ edition, New Delhi: Prentice hall of India. 2006;86-160.

[23] Suresh KP, Chandrasekhar S. Sample size estimation and power analysis for clinical research studies. Journal Human Reproduction Science. 2012;5(1):07-13.

[24] DeSanctis JT, Lee MJ, Gazelle GS, Boland GW, Halpern EF, Saini S, et al. Prognostic indicators in acute pancreatitis: CT vs APACHE II. Clin Radiol. 1997;52:842-48.

[25] Clavien PA, Hauser $H$, Meyer P, Rohner A. Value of contrast-enhanced computerized tomography in the early diagnosis and prognosis of acute pancreatitis: A prospective study of 202 patients. Am J Surg. 1988;155:457-66.
[26] Ranson JH. Diagnostic standards for acute pancreatitis. World J Surg. 1997;21:136-42.

[27] Durmaz M, Arslan S, Özbakır B, Güngör G, Tolu I, Arslan F, et al. Effectiveness of shear wave elastography in the diagnosis of acute pancreatitis on admission. Medical Ultrasonography. 2018;20(3):278.

[28] Göya C, Hamidi C, Hattapoğlu S, Çetinçakmak M, Teke M, Degirmenci $\mathrm{M}$, et al. Use of acoustic radiation force impulse elastography to diagnose acute pancreatitis at hospital admission. Journal of Ultrasound in Medicine. 2014;33(8):1453-60.

\section{PARTICULARS OF CONTRIBUTORS:}

1. Associate Professor, Department of Radiodiagnosis, Mysore Medical College and Research Institute, Mysuru, Karnataka, India.

2. Head, Department of Radiodiagnosis, Mysore Medical College and Research Institute, Mysuru, Karnataka, India.

3. Associate Professor, Department of Radiodiagnosis, Mysore Medical College and Research Institute, Mysuru, Karnataka, India.

4. Senior Resident, Department of Radiodiagnosis, Mysore Medical College and Research Institute, Mysuru, Karnataka, India.

5. Senior Resident, Department of Radiodiagnosis, Mysore Medical College and Research Institute, Mysuru, Karnataka, India.

6. Senior Resident, Department of Radiodiagnosis, Mysore Medical College and Research Institute, Mysuru, Karnataka, India.

7. Postgraduate, Department of Radiodiagnosis, Mysore Medical College and Research Institute, Mysuru, Karnataka, India.

8. Postgraduate, Department of Radiodiagnosis, Mysore Medical College and Research Institute, Mysuru, Karnataka, India.

\section{NAME, ADDRESS, E-MAIL ID OF THE CORRESPONDING AUTHOR:} Dr. KN Rashmi,

\#31, Janayithri, $5^{\text {th }}$ cross, A.E.C.S Layout, Ashrama Colony, Sanjaynagar, Bangalore-560094, Karnataka, India.

E-mail: rashmi.k.nag@gmail.com
PLAGIARISM CHECKING METHODS: [Jain Het al.]

- Plagiarism X-checker: Aug 08, 2020

- Manual Googling: Nov 07, 2020

- iThenticate Software: Jan 12, 2021 (23\%)

\section{AUTHOR DECLARATION:}

- Financial or Other Competing Interests: None

- Was Ethics Committee Approval obtained for this study? Yes

- Was informed consent obtained from the subjects involved in the study? Yes

- For any images presented appropriate consent has been obtained from the subjects. Yes

Date of Submission: Aug 06, 2020

Date of Peer Review: Oct 03, 2020

Date of Acceptance: Nov 07, 2020

Date of Publishing: Apr 01, 2021 